\title{
Disentangling the driving force of pyramidal firms' capital structure: a new perspective
}

\begin{abstract}
Purpose: The purpose of this paper is to disentangle the driving force of pyramidal firms' capital structure from nine East Asian economies.

Design/methodology/approach: To disentangle the driving force, this paper develops a new theoretical framework for the pyramidal firms'. Using panel regression, the new theoretical framework is tested on a set of 1,433 pyramidal firms covering a period from 1992 to 1997.

Findings: The regression results reveal that the separation of cash flow rights and control rights in the pyramidal firms have led to high usage of leverage for the purpose of preserving the ultimate owners' (UO) dominance in the pyramidal firms that he or she controls. Based on the findings, the study concludes that the actual driving force of the pyramidal firms' capital structure is the UO non-dilution entrenchment motive.

Originality/value: The main contribution of this paper is the new theoretical framework developed which enable us to disentangle the driving force behind pyramid firm's capital structure.
\end{abstract}

Keyword: Capital structure; Corporate governance; South East Asia; Far East 